\title{
Notes
}

\section{Versatile and Efficient Conversion of Thiols into Disulfides by Poly(4-vinylpyridinium tribromide) as Reusable Oxidizing Polymer}

\author{
Arash Ghorbani-Choghamarani, ${ }^{*}$ Mohsen Nikoorazm, Hamid Goudarziafshar, and Mina Abbasi ${ }^{\dagger}$ \\ Department of Chemistry, Faculty of Science, Ilam University, P.O. Box 69315516, Ilam, Iran \\ *E-mail: arashghch58@yahoo.com,a.ghorbani@mail.ilam.ac.ir \\ ${ }^{\dagger}$ Islamic Azad University, Science and Research, Branch-Ahvaz, Ahvaz, Iran \\ Received September 24, 2010, Accepted November 20, 2010
}

Key Words: Thiols, Disulfides, Poly(4-vinylpyridinium tribromide), Poly(4-vinylpyridin), Oxidation

The conversion of thiols to disulfides is of considerable interest in chemical, biological, and industrial points of view. ${ }^{1-4}$ The classical procedures for this type of reaction use reagents such as silica- $\mathrm{PCl}_{5} / \mathrm{NaNO}_{2},{ }^{2} \mathrm{NaBrO}_{3} / \mathrm{NaBr},{ }^{3}$ 1-chlorobenzotriazole, ${ }^{5}$ rosolic acid, ${ }^{6}$ polyvinylpyrrolidone (PVP)-capped silver nanoparticles, ${ }^{7} \mathrm{H}_{2} \mathrm{O}_{2} / \mathrm{NaI}^{8},{ }^{8} \mathrm{CeCl}_{3} \cdot 7 \mathrm{H}_{2} \mathrm{O} / \mathrm{I}_{2},{ }^{9}$ molybdate sulfuric acid/ $/ \mathrm{NaNO}_{2}{ }^{10}$ silica sulfuric acid/ $/ \mathrm{NaNO}_{2}{ }^{11}$ ethylenebis $\left(\mathrm{N}\right.$-methylimidazolium) chlorochromate, ${ }^{12}$ wet $\mathrm{NaIO}_{4}{ }^{13} \mathrm{~N}$ phenyltriazolinedione, ${ }^{14}$ monochloro poly(styrenehydantoin), ${ }^{15}$ and urea-hydrogen peroxide (UHP)/maleic anhydride. ${ }^{16}$

There are a variety of reports on the functionalization of organic compounds with molecular bromine. ${ }^{17-22}$ In order to decrease the toxicity of molecular bromine, a variety of organic tribromide reagents were reported and applied in different functional group transformations. ${ }^{22-27}$ In this light we became interest to prepare a new and reusable tribromide reagent.

In continuing of our attempts to introduce new methodologies for organic functional group transformations, ${ }^{28-36}$ we became interested to prepare a new and recoverable polymeric tribromide reagent. Therefore we decided to prepare poly(4-vinylpyridinium tribromide) from poly(4-vinylpyridin) as is outline in Scheme 1.

In order to investigate the oxidizing properties of poly(4vinylpyridinium tribromide), a wide range of thiols were subjected to oxidative coupling to produce corresponding disulfides by this polymeric reagent.

Initially, to find an appropriate solvent for the oxidative coupling of thiols by poly(4-vinylpyridinium tribromide), 2-mercaptobenzothiazole, as standard example, was treated with poly(4-vinylpyridinium tribromide) in different solvents.
Table 1. Oxidative coupling of 2-mercaptobenzothiazole into 1,2-bis (2-benzothiazol)disulfane using poly(4-vinylpyridinium tribromide) in different solvents at room temperature ${ }^{a}$

\begin{tabular}{cccc}
\hline Entry & Solvent & Time $(\mathrm{min})$ & ${\text { Yield }(\%)^{b}}^{b}$ \\
\hline 1 & Acetone & 120 & $-c$ \\
2 & Chloroform & 40 & 95 \\
3 & Dichloromethane & 40 & 98 \\
4 & $n$-Hexane & $24 \mathrm{~h}$ & - \\
5 & Ethyl acetate & 120 & 42 \\
6 & Ethanol & 65 & 88 \\
7 & Acetonitrile & 120 & $-c$
\end{tabular}

${ }^{a}$ 2-mercaptobenzothiazole/poly(4-vinylpyridinium tribromide)/solvent $=$ $1 \mathrm{mmol}: 0.277 \mathrm{~g}: 5 \mathrm{~mL}$. ${ }^{b}$ Isolated yield (product purified by column chromatography). ${ }^{c}$ Reaction didn't complete and a few spots was observed on TLC. ${ }^{d}$ No reaction.

The oxidative coupling of 2-mercaptobenzothiazole was carried out via mixing $1 \mathrm{mmol}$ of substrate with $0.277 \mathrm{~g}$ of poly(4vinylpyridinium tribromide) in $5 \mathrm{~mL}$ of organic solvent at room temperature. The results including reaction times and product yields summarized in Table 1.

As is evident from Table 1, dichloromethane and chloroform are the better solvents in terms of selectivity and reactivity. But we decided to use dichloromethane as reaction solvent in all coupling reaction, because of its lower boiling point, which allow doing the work up process with lower energy.

Eventually, with optimal conditions in hand a variety of aliphatic and aromatic thiols 1 converted into corresponding disulfides 2 using poly(4-vinylpyridinium tribromide) in dichloromethane at room temperature (Scheme 2 and Table 2).

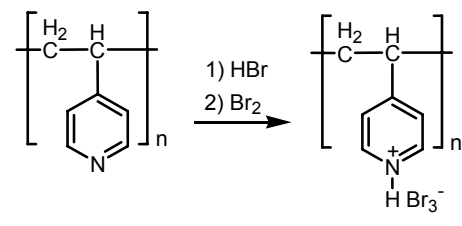

Scheme 1

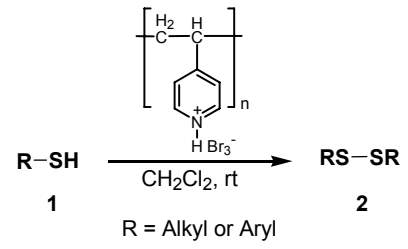

Scheme 2 
Table 2. Oxidative coupling of thiols into disulfides by poly(4-vinylpyridinium tribromide) in dichloromethane at room temperature ${ }^{a}$

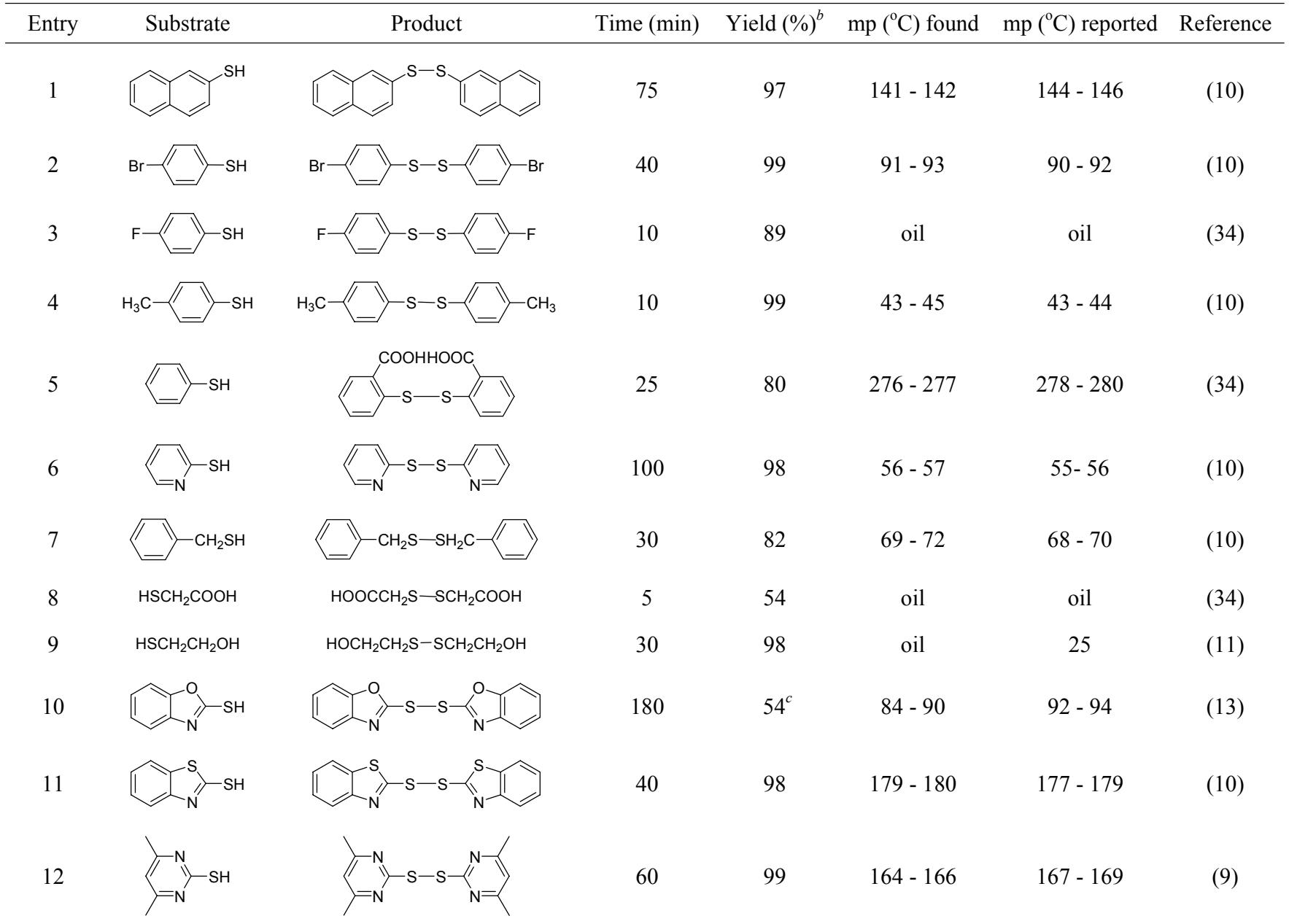

${ }^{a}$ Substrate/poly(4-vinylpyridinium tribromide) for entries of 1-11 $(1 \mathrm{mmol} / 0.277 \mathrm{~g})$ for entry $12(1 \mathrm{mmol} / 0.346) .{ }^{b}$ Isolated yield (product purified by column chromatography). ${ }^{c}$ Disulfide isolated by preparative TLC.

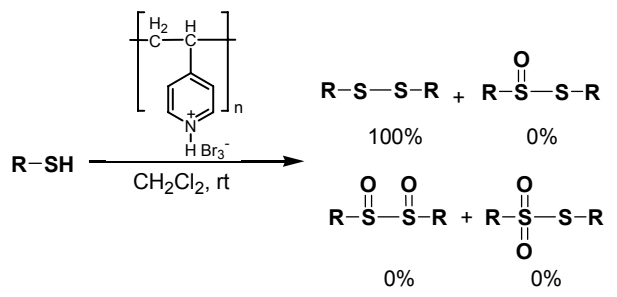

Scheme 3

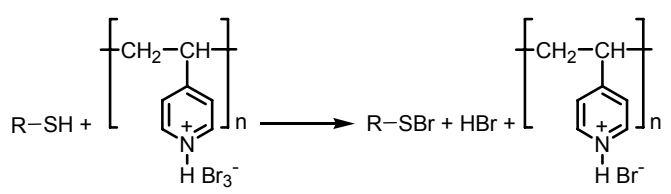

$2 \mathrm{R}-\mathrm{SBr} \longrightarrow \mathrm{RS}-\mathrm{SR}+\mathrm{Br}_{2}$

$\mathrm{R}-\mathrm{SH}+\mathrm{Br}_{2} \longrightarrow \mathrm{R}-\mathrm{SBr}+\mathrm{HBr}$

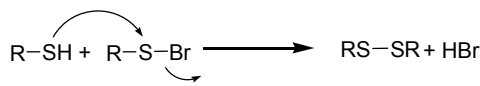

Scheme 4
All of the reactions were proceeded under completely heterogeneous conditions via mixing of a thiol with poly(4-vinylpyridinium tribromide) in dichloromethane and stirring this mixture for appropriate time at room temperature. Resulting disulfide purified by short column chromatography. Because of mild and heterogeneous conditions of described system, there is no overoxidation to sulfoxide or sulfone was observed (Scheme 3).

A plausible mechanism for the oxidative coupling of thiols by poly(4-vinylpyridinium tribromide) is outlined in Scheme 4.

Presumably, the reaction proceed through bromonium transfer from poly(4-vinylpyridinium tribromide) to thiol to yield sulfenyl bromide. The molecules of sulfenyl bromide couple with each other to produce disulfide and molecular bromine. The molecular bromine reacts with thiol again and finally produces another molecule of disulfide.

Reusability of Poly(4-vinylpyridinium tribromide). An important advantage of the use of poly(4-vinylpyridinium tribromide) is the facile recovery from the reaction mixture and the reusability. After reaction completion, poly(4-vinylpyridinium bromide) can be easily isolated via simple filtration. It could be converted to poly(4-vinylpyridinium tribromide) by reaction with bromine $\left(\mathrm{Br}_{2}\right)$ again (Scheme 5). 


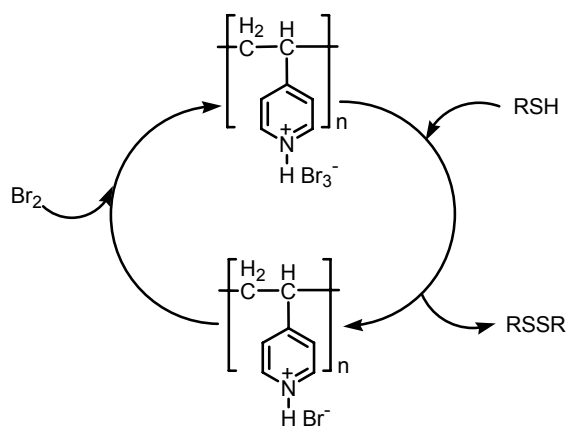

Scheme 5

Table 3. Reusability of poly(4-vinylpyridinium tribromide) in the oxidative coupling of 4,6-dimethylpyrimidine-2-thiol

\begin{tabular}{ccc}
\hline Run no & Time (min) & ${\text { Yield }(\%)^{a}}^{a}$ \\
\hline 1 & 60 & 99 \\
3 & 10 & 99 \\
4 & 55 & 98 \\
5 & 25 & 98 \\
\end{tabular}

${ }^{a}$ Isolated yield (product purified by column chromatography).

As is evident from Table 3, activity of poly(4-vinylpyridinium tribromide) did not show any significant decrease after five runs.

In summary, in this research project we introduce a new type of tribromide reagent with polymeric structure. This insoluble, powdery reagent allows a simple recovery procedure. The features of short reaction time, good yields of products, no environmental pollution, and reusability of the reagent make this method attractive for organochemists.

\section{Experimental}

General. The chemicals and solvents were purchased from Fluka, Merck and Aldrich chemical companies without further purifications. All products are known and were characterized by comparison of their spectral (IR, ${ }^{1} \mathrm{H} N M R$, or ${ }^{13} \mathrm{C} N M R$ ) and physical data with authentic samples.

Preparation of Poly(4-vinylpyridinium tribromide). In a $50-\mathrm{mL}$ round-bottomed flask, $1 \mathrm{~mL}$ of $\mathrm{HBr}(47 \%)$ and $1.85 \mathrm{~g}$ of poly(4-vinylpyridine) was stirred for 1 hours, then kept at $50^{\circ} \mathrm{C}$ for 24 hours to obtain dry poly(4-vinylpyridinium bromide). In the next step $1.2 \mathrm{~mL}$ of $\mathrm{Br}_{2}$ was added to the resulting powder; this mixture stirred for 2 hours and an orange crystalline solid, poly(4-vinylpyridinium tribromide), was obtained quantitatively. ${ }^{37}$

General Procedure for the Oxidative Coupling of Thiols by Poly(4-vinylpyridinium tribromide). To a suspension of poly (4-vinylpyridinium tribromide) in dichloromethane $(5 \mathrm{~mL})$ one of the thiols was added, and the mixture was stirred at room temperature for the specified time (Table 2) the reaction progress was monitored by TLC. After reaction completion crude product was purified by short column chromatography using dichloromethane (for entries 1-4 and 7), $n$-hexane/acetone 4:6 (for entries 11 and 12) or ethanol (for entries 5, 6,8 and 9) as eluent. Finally solvents were evaporated and pure disulfide was obtained.

Entry 10 was purified by preparative TLC using $n$-hexane/ acetone $8: 2$ as eluent.

Acknowledgments. This work was supported by the research facilities of Ilam University, Ilam, Iran.

\section{References}

1. Ghafuri, H.; Hashemi, M. M. J. Sulfur Chem. 2009, 30, 578.

2. Pathak, U.; Pandey, L. K.; Mathur, S. Synthetic Commun. 2009, 39, 2923.

3. Joshi, G.; Bhadra, S.; Ghosh, S.; Agrawal, M. K.; Ganguly, B.; Adimurthy, S.; Ghosh, P. K.; Ranu, B. C. Ind. Eng. Chem. Res. 2010, 49, 1236.

4. Trivedi, M. V.; Laurence, J. S.; Siahaan, T. J. Curr. Protein Pept. Sci. 2009, 10, 614 .

5. Stellenboom, N.; Hunter, R.; Caira, M. R. Tetrahedron 2010, 66, 3228.

6. Singh, W. M.; Baruah, J. B. Synthetic Commun. 2009, 39, 325.

7. Jiangmei, Y.; Huiwang, T.; Muling, Z.; Jun, T.; Shihong, Z.; Zhiying, Y.; Wei, W.; Jiaqiang, W. Chin. J. Catal. 2009, 30, 856.

8. Kirihara, M.; Asai, Y.; Ogawa, S.; Noguchi, T.; Hatano, A.; Hirai, Y. Synthesis 2007, 3286.

9. Silveira, C. C.; Mendes, S. R. Tetrahedron Lett. 2007, 48, 7469.

10. Montazerozohori, M.; Karami, B.; Azizi, M. Arkivoc 2007, 99.

11. Zolfigol, M. A. Tetrahedron 2001, 57, 9509.

12. Hosseinzadeh, R.; Tajbakhsh, M.; Khaledi, H.; Ghodrati, K. Monatsh. Chem. 2007, 138, 871.

13. Montazerozohori, M.; Joohari, S.; Karami, B.; Haghighat, N. Molecules 2007, 12, 694.

14. Christoforou, A.; Nicolaou, G.; Elemes, Y. Tetrahedron Lett. 2006, 47, 9211.

15. Akdag, A.; Webb, T.; Worley, S. D. Tetrahedron Lett. 2006, 47, 3509 .

16. Karami, B.; Montazerozohori, M.; Habibi, M. H. Molecules 2005 , 10, 1358.

17. Uyanik, M.; Fukatsu, R.; Ishihara, K. Chem.-Asian J. 2010, 5, 456.

18. Wakabayashi, H.; Irinamihira, O.; Shibata, S.; Kurihara, T.; Uchiyama, Y.; Ohta, A.; Fujimori, K. Hererocycles 2008, 76, 1133.

19. Harn, P. J.; Lin, C. C.; Wu, H. J. J. Chin. Chem. Soc. 2008, 55, 233.

20. Oae, S.; Onishi, Y.; Kozuka, S.; Tagaki, W. Bull. Chem. Soc. Jpn. 1966, 39, 364

21. Ali, M. H.; Bohnert, G. J. Synthesis 1998, 1238.

22. Ali, M. H.; Stricklin, S. Synthetic Commun. 2006, 36, 1779.

23. Yavari, I.; Shaabani, A. J. Chem. Res.-S 1994, 7, 274.

24. Heravi, M. M.; Derikvand, F.; Ghassemzadeh, M.; Neumuller, B. Tetrahedron Lett. 2005, 46, 6243.

25. Zolfigol, M. A.; Chehardoli, G.; Salehzadeh, S.; Adams, H.; Ward, M. D. Tetrahedron Lett. 2007, 48, 7969.

26. Joshaghani, M.; Rafiee, E.; Shahbazi, F.; Jafari, H.; Amiri, S.; Omidi, M. Arkivoc 2007, 164.

27. Joshaghani, M.; Khosropour, A. R.; Jafary, H.; MohammadpoorBaltork, I. Phosphorous, Sulfur, Silicon, Relat. Elem. 2005, 180, 117.

28. Ghorbani-Choghamarani, A.; Goudarziafshar, H.; Nikoorazm, M.; Yousefi, S. Lett. Org. Chem. 2009, 6, 535.

29. Ghorbani-Choghamarani, A.; Rezaei, S. J. Chin. Chem. Soc. 2009, $56,251$. 
30. Ghorbani-Choghamarani, A.; Goudarziafshar, H.; Nikoorazm, M.; Yousefi, S. Can. J. Chem. 2009, 87, 1144.

31. Ghorbani-Choghamarani, A.; Hajjami, M.; Goudarziafshar, H.; Nikoorazm, M.; Mallakpour, S.; Sadeghizadeh, F.; Azadi, G. Monatsh. Chem. 2009, 140, 607.

32. Ghorbani-Choghamarani, A.; Zolfigol, M.A.; Rastegar, T. Chin. J. Catal. 2009, 30, 273.

33. Goudarziafshar, H.; Ghorbani-Choghamarani, A.; Nikoorazm, M.; Naserifar, Z. Chin. J. Chem. 2009, 27, 1801
34. Ghorbani-Choghamarani, A.; Nikoorazm, M.; Goudarziafshar, H.; Tahmasbi, B. Bull. Korean Chem. Soc. 2009, 30, 1388.

35. Ghorbani-Choghamarani, A.; Nikoorazm, M.; Goudarziafshar, H.; Shiri, L.; Chenani, Z. Bull. Korean Chem. Soc. 2009, 30, 972.

36. Ghorbani-Choghamarani, A.; Goudarziafshar, H.; Rezaee, S.; Mortazavi, S. S. Chin. Chem. Lett. 2009, 20, 415.

37. Ghorbani-Choghamarani, A.; Zolfigol, M. A.; Hajjami, M.; Darvishi, K.; Gholamnia, L. Collect. Czech. Chem. Commun. 2010, 75,607 . 